\title{
Cultura Cultura
}

\section{O problema do conhecimento em Diamantino Martins}

The Problem of Knowledge in Diamantino Martins

\section{Cristiana de Soveral e Paszkiewicz}

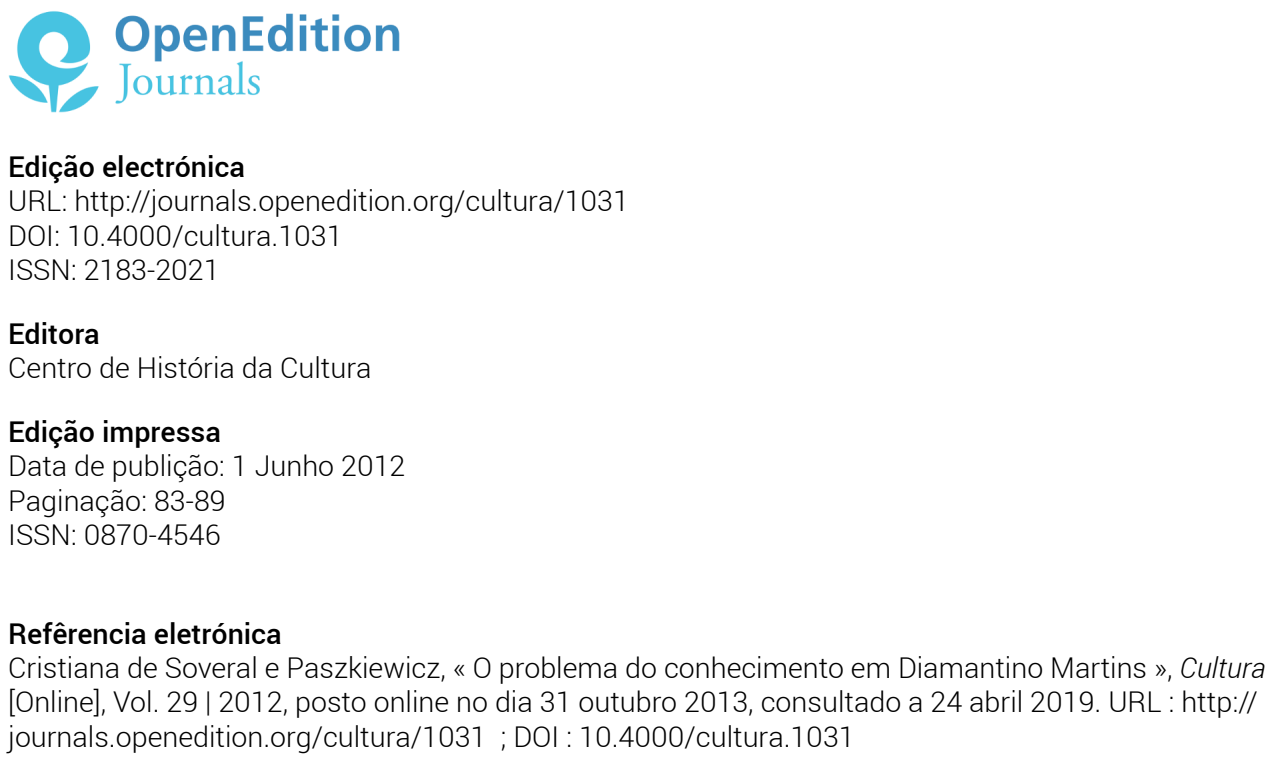

Este documento foi criado de forma automática no dia 24 Abril 2019.

(c) CHAM - Centro de Humanidades / Centre for the Humanities 


\section{O problema do conhecimento em Diamantino Martins}

The Problem of Knowledge in Diamantino Martins

Cristiana de Soveral e Paszkiewicz

1 Toda a formação de Diamantino Martins foi feita no seio do pensamento neoescolástico, do qual acolhe a motivação fundamental de renovação de um pensamento filosófico cristão, no espírito da escola neotomista de Lovaina. Esta renovação exigiu uma aproximação às novas e recentes filosofias do seu tempo, aproveitando o que delas emergia com mais vitalidade. É esse diálogo inteligente e original que o padre Diamantino Martins estabelece ao longo de toda a sua obra, num incansável esforço de actualidade. Das correntes do existencialismo, passando pela fenomenologia, até às então recentes descobertas das teorias psicanalíticas, o diálogo de D.M. é vivo e dinâmico, procurando nestes os melhores fundamentos para justificar a Metafísica enquanto saber globalizante e totalizador do ser humano, sobre si mesmo, sobre o Mundo e sobre Deus, configurandose numa nova Teodiceia à qual chama de Teodiceia Existencial. Num texto de 1954, com o título sugestivo de «A ideia de Deus e a civilização de hoje» afirma: «não pode agora fazerse como se o fenomenologismo e as filosofias da existência não tivessem chamado a atenção para o valor absoluto do que unicamente existe, o indivíduo, e a nova concepção da filosofia, que integrando as demais se impõe» (1954: 331) ${ }^{1}$.

2 A posição gnosiológica de D.M. é indissociável da sua posição existencialista.

3 A inteligência humana tende à totalidade e à unicidade do ser, o que levou os filósofos à tentação de construir sistemas com valor absoluto e universal. Mas questiona o filósofo: qual a essência de um sistema? Não corresponde um sistema a um conjunto de verdades logicamente organizadas no qual ao nexo entre os elementos se junte, simultaneamente, a verdade de cada um deles? Ora o mais perfeito sistema, o único capaz de manter a verdade dos seus elementos, seria aquele que nos desse «uma ordem lógica coincidindo com a ordem ontológica, fazendo-nos assistir à própria ontogénese do ser» (1956: 302), a experimentação do ser em toda a sua onticidade. Mas previne-nos o autor: «um sistema assim não é viável, temos de contentar-nos com uma visão ordenada da realidade (...) 
como ponto de apoio para a determinação da ordem real do ser na sua essencialidade (...) não se trata de uma ordem lógica da explicação (...) mas da compreensão da ordem apreendida» (1956: 302). A existência só se pensa verdadeiramente quando se pensa a consistência do ser existente. E alerta o autor: «não é o filósofo (...) que explica o ser; é o ser que se explica a si mesmo, ao mostrar-se como é. 0 que o filósofo faz é compreender esta explicação» (1956: 303).

4 A filosofia, afirma, consiste numa busca das razões ontológicas do real, razões estas que saem da vivência existencial do ser mas que também se buscam na compreensão da sua finalidade, na procura da sua natureza íntima e essencial. 0 homem é uma potência que se actualiza na existência, como dissera Aristóteles. O sistema filosófico é um sistema simultaneamente explicativo do ser e do Ser, do homem e de Deus. A filosofia é Metafísica, e a análise do conhecimento é ponto fundamental para a construção da ontologia do ser.

5 Um dos primeiros problemas que o autor põe é a falência das chamadas Filosofias da Essência, por colocarem no centro da atenção gnosiológica as relações entre ideias formadas por abstracção, desligadas do real. «Não pode separar-se o pensamento abstracto da existência (...) se não se quer tirar o pensamento humano do meio que lhe é próprio» (1948: 148).

6 Uma coisa é atingir a evidência das coisas, que obtemos pelo conhecimento directo da realidade, outra é a procura das coisas evidentes, que coloca em marcha o pensamento reflexo. Neste, o que se procura não é a realidade em si mas a Teoria da Realidade. Aqui, pensa-se o «pensamento das coisas» e não «as coisas mesmas».

7 O maior erro das Filosofias da Essência foi confundir a "Teoria do ser" com o "ser mesmo", objectivando modos de ser que são apenas modos de conhecer, transferindo para o objecto exterior o que apenas é próprio do sujeito, passando da objectividade das essências apreendidas na sua existência concreta para a objectivação da maneira de conhecer. Ao afirmar existências com base nas razões lógicas, transfere o nexo existencial. Mas, diz-nos o autor, «o conhecimento das essências difere do conhecimento do nexo causal que as une» (1948: 145).

80 conhecimento é sempre de um objecto, e neste sentido o conhecimento é sempre objectivo. Contudo, o autor distingue entre o objecto sensível, que se apreende directamente do real pela percepção, e o objecto enquanto realidade pensada. O homem apreende o objecto sensível directamente, mas também directamente apreende a «apreensão», experimentando sua vida espiritual. E explica o autor: «atingimos, portanto, as qualidades metafísicas dos acidentes espirituais humanos, tão imediatamente em si como conhecemos as qualidades metafísicas dos acidentes sensíveis. A dificuldade de admitir esta posição vem de se exigir para o conhecimento do espiritual humano mais do que se exige para o conhecimento do mundo sensível, querendo que se conheça a alma na sua substancialidade física, o que não se exige para o conhecimento do mundo sensível e (...) é a partir da nossa experiência espiritual que nós pensamos os demais homens, na sua espiritualidade» (1961(a): 58). O filósofo toma uma posição anti-substancialista.

10 Este foi o problema dos Universais, tal como o coloca D.M., que se manteve indiferente à realidade mesma. $O$ vazio existencial que emana do mundo construído por representações abstractas vem do esquecimento de que só o concreto existe. 0 resultado foi o 
desconhecimento «tanto do pensamento como do eu na sua onticidade, bem como do mundo e Deus» (1948: 156).

11 A verdade é o objecto próprio do conhecimento humano, é um factor de unificação do ser, mas só a verdade total satisfaz plenamente o homem. A verdade atinge-se, quer directamente da experiência, através da apreensão imediata da realidade, quer imediatamente, através do pensamento. Contudo, para o autor, é o conhecimento intuitivo da realidade que melhor satisfaz a inteligência humana, e o segundo modo de compreender a realidade está intrinsecamente dependente do primeiro.

12 Mesmo no autoconhecimento se encontram estes diferentes graus de profundidade da verdade. Encontramo-nos «sendo» e depois, procuramos saber «o que somos». Dois graus de verdade: pela acção vive-se a verdade ôntica, pelo pensamento conhece-se a verdade lógica. Contudo, para se atingir a verdade ontológica é necessário admitir a existência da verdade lógica, pois a verdade lógica nada mais é do que a conformidade da inteligência com o real. Mas não se pode deduzir a verdade ontológica da lógica e é necessário não esquecer que toda a verdade lógica tem a sua verdade apoiada na verdade ontológica ou existencial.

13 A inteligência que abstrai é a mesma que intui, a nossa compreensão do mundo resulta de uma intuição-abstraç̧ão. Mas é o mundo construído pelo pensamento sem nexo com a realidade, puro sistema de abstracções «onde só se predicam essências de essências sem preocupações da existência» (1954: 328), que o autor rejeita. É o mundo das representações metafísicas construídas a priori e sem valor ontológico que D.M. quer substituir pelo mundo da realidade existencial. Em vez do mundo "como se constrói" é o mundo "como existe" que sobretudo interessa ao conhecimento. Contudo, adverte o filósofo: Só conseguimos conhecer o ser que temos na consciência, nunca o ser na sua onticidade absoluta.

E, reafirma o filósofo, o ser é mais do que conhecer.

15 O ser pensado não tem realidade ôntica, não tem realidade existencial. O pensamento não cria o ser, apenas pensa o ser, o qual possui, para além desse pensamento, uma realidade existencial. Diamantino Martins assume, claramente, uma posição realista em oposição ao idealismo.

16 É um erro considerar a verdade separada dos demais problemas da vida, «não basta compreender a verdade apenas conceitualmente, sem a vivência dela» (1949: 373). Não é possível, diz-nos D.M., desligar o conhecimento da aç̧ão. «A atitude verdadeira perante a realidade implica conhecimento verdadeiro e a rectitude da acção a que está junta» (1949: 382). É a acção, a experiência vivencial e a apreensão imediata da realidade que irão dar ao pensamento os seus elementos. Intuição ou verdade ôntica apreendida directamente e reflexão ou verdade lógica, que se obtém pelo pensamento da primeira. Duas verdades inseparáveis. Se queremos ser e conhecer perfeitamente, temos que aceitar toda a realidade.

o homem é mais plenamente na medida em que melhor actualiza a realidade; na medida em que interioriza o «outro» e disso tem consciência. É esse processo de consciencialização que lhe dá o autoconhecimento - percebe-se como sendo, na medida em que vai sendo com o outro. É este processo que revela ao homem o seu próprio euôntico, o qual ele vai actualizando. Do ponto de vista psicológico, o eu-ôntico é-lhe tão estranho e exterior como o «outro», ou como o mundo. 
18 Não basta sermos onticamente, é necessário ter consciência do ser e pensar o nosso ser. «O ser pleno é o ser concretíssimo, o ser que se é onticamente (...) importa (...) no plano do ser, ser plenamente, e no plano do conhecer, conhecer plenamente esse ser ôntico, a todos os seus níveis» (1966(b): 249). É o ôntico conhecido que nos actualiza, é o "ontológico". O valor da personalidade está intimamente ligado a esta consciência e a este pensar. Existir é co-existir, diz-nos D.M. Co-existir é ter o «outro» presente em nós, cuja forma mais sublime é o amor, onde a presença do outro se faz plenamente.

19 A inteligência tende ao Total, ao englobante, como dizíamos, e para D.M. é pela inteligência plasmada no pensamento do homem singular que este atinge o seu ser na sua unicidade radical e só através dele atingirá o Ser que coincidirá com toda a Verdade.

É no interior do homem que se encontra esse «eu fontal», unificador, que revela a essência do homem ao próprio homem. Será pelas psicologias da profundidade que melhor se chega ao uno-profundo do homem, onde a natureza humana se manifesta ${ }^{2}$.

21 Mas perguntamos: haverá, então, um «homem geral» com uma essência comum, apesar de só pessoalmente experimentada? Poder-se-á, mesmo por analogia, pensar o «outro» como «nós mesmos»? A resposta do filósofo jesuíta é afirmativa: «Em toda a actividade humana (...) se deve revelar a essência humana, não sendo necessária a indução senão para precisar a natureza dessa essência» (1961(a): 34). É pela experiência do eu-profundo, na plenitude de toda a sua humanidade, vivida e experimentada pelo eu concreto, que chego à essência do homem, porque ela me revelará a própria natureza humana na sua génese. A experiência que tenho em mim mesmo do meu «eu-profundo» é semelhante à do «outro». Descrevê-la, tal como a experimento, revelará a essência do homem ao próprio homem. «Em vez da unidade lógica da multiplicidade dos actos humanos, investigamos a todos os níveis a unidade ôntica do princípio donde esses actos provêm, buscando para lá dos quereres particulares um querer fundamental» (1961(a): 41). Só depois a Teoria do Homem será possível. «A filosofia tem de começar por ser descoberta do ser, para terminar em teoria do ser descoberto» (1955: 92). E clarifica o autor: a consciência, antes de conceptualizar, atende ao dado, na sua existência concreta. Só depois o conceptualiza e lhe atribui um nome.

Mas voltemos a perguntar: não será esse conceito, ainda assim, um abstracto? Sim responde o filósofo -, mas um abstracto verdadeiro. A crítica do conhecimento faz-se ao nível da sua descrição fenomenológica, na descoberta do ser na sua onticidade, porque o conhecimento orienta-se, em primeira mão, para as "coisas verdadeiras» e só num segundo plano para o "verdadeiro abstracto». A essência que o homem busca é a metafísica, não a física; daí D. M. reafirmar que toda a psicologia se prolonga numa metafísica.

Poderíamos dizer que D. M. procurou a síntese entre a Filosofia da existência e a Filosofia da essência.

Na obra de 1957, O Problema de Deus, mais do que em qualquer outra, D.M. apresenta-nos o caminho do ser na sua viagem interior, na sua vivência profunda de imanência até chegar ao Absoluto e ao Deus pessoal.

Percebe-se, pelo que acabámos de expor sobre as reflexões do autor, a inutilidade que para ele têm todas as tentativas «demonstrativas» da existência de Deus. É no âmbito de uma metafísica existencial que esse encontro se compreende. Uma coisa é chegar a Deus como "causa primeira" ou como "fim último"; outra, muito diferente, é ter uma experiência directa da sua existência, é possuir a sua presença em nós. Ninguém se dispõe 
a amar uma "causa primeira". 0 amor é uma experiência vivencial, de total presença do «outro» em nós; é possuirmos em nós um outro-ser-pessoal. E neste sentido o conhecimento «é, acima de tudo, relação entre sujeitos (...) pois apenas o amor possibilita que o objecto seja atingido na sua totalidade» ${ }^{3}$. Esta experiência directa do ser com o Ser, do homem com Deus, pode-se ter pela experiência da oração, diz-nos o padre D.M., mas a expressão mais perfeita têm-na os místicos. pensar a Deus, embora saibamos de antemão que teremos sempre que caminhar num aprofundamento sem fim...

\section{NOTAS}

1. Incluímos, por ordem cronológica, apenas as obras de D.M. consultadas no âmbito deste trabalho, as quais passarão a ser referidas somente pela data:

"Verdade e Vida", Revista Portuguesa de Filosofia, Tomo II, Braga, 1946, pp. 5-18.

"Posição existencial do Homem no Universo", Revista Portuguesa de Filosofia, Tomo IV, Fasc. 2, Braga, 1948, pp. 131-161.

“No Caminho do Ser Total”, Revista Portuguesa de Filosofia, Tomo V, Fasc. 3, Braga, 1949, pp. 289-306.

“Pensamento e acção", Revista Portuguesa de Filosofia, Tomo V, Fasc. 4, Braga, 1949, pp. 371-386.

"A admissão espontânea de Deus - Um problema de ontologia directa", Revista Portuguesa de Filosofia, Tomo VI, Fasc. 2, Braga, 1950, pp. 184-186. 
“A ideia de Deus e a Civilização de hoje”, Revista Portuguesa de Filosofia, Tomo X, Fasc. 3, Braga, 1954, pp. 325-340.

Existencialismo, Braga: Liv. Cruz, 1955 (a).

"Sobre o problema da filosofia cristã", Actas do I Congresso Nacional de Filosofia, Braga, 1955(b), pp. 362-371.

“Deus no sistema de Santo Agostinho", Revista Portuguesa de Filosofia, Tomo XI, Vol. I, Fasc. 2, Braga, 1955(c), pp. 177-189.

"Valor dos sistemas em filosofia", Revista Portuguesa de Filosofia, Tomo XII, Fasc. 3, Braga, 1956, pp. 131-161.

O Problema de Deus, Braga: Liv. Cruz, 1957(a).

Teoria do Conhecimento, Braga: Liv. Cruz, 1957(b).

Mistério do Homem - Ser, personalidade, imortalidade, Braga: Liv. Cruz, 1961(a).

“A vida como sagrado", Revista Portuguesa de Filosofia, Tomo XVII, Fasc. 3, Braga, 1961(b), pp. 151-163.

Imagem do Mundo - Da beleza até Deus, Braga: Liv. Cruz, 1963(a).

"Infra-estruturas da vida moral", Revista Portuguesa de Filosofia, Tomo XIX, Fasc. 1, Braga, 1963(b), pp. 3-20.

“Alguns problemas dos Universais", Revista Portuguesa de Filosofia, Tomo XIX, Fasc. 4, Braga, 1963 (c), pp. 345-365.

Do Inconsciente - Estudos de psicologia de profundidade, Braga: Liv. Cruz, 1964.

“Essência religiosa do homem”, Revista Portuguesa de Filosofia, Tomo XXI, Fasc. 2, Braga, 1965, pp. 121-133.

Filosofia da Plenitude, Braga: Liv. Cruz, 1966(a)

"A quebra da Soledade", Revista Portuguesa de Filosofia, Tomo XXII, Fasc. 3, Braga, 1966(b), pp. 245-257.

"O problema da demonstração de Deus em Kierkegaard", Revista Portuguesa de Filosofia, Tomo XXIV, Fasc. 4, Braga, 1968, pp. 429-439.

"Pressupostos e condições duma teodiceia existencial", Revista Portuguesa de Filosofia, Tomo XXVII, Fasc. 4, Braga, 1971, pp. 346-356.

2. Ver Paszkiewicz, Cristiana de Soveral," o diálogo de Diamantino Martins com a psicanálise", Braga, 2010.

3. Ver Braz Teixeira, António, A Filosofia da Escola Bracarense, Braga, 2010, p. 60.

\section{RESUMOS}

O presente artigo procura clarificar a posição gnosiológica de Diamantino Martins. Partindo de uma posição existencialista, o autor afirma a falência das chamadas Filosofias da Essência, por colocarem no centro da atenção gnosiológica as relações entre ideias formadas por abstracção, desligadas do real.

Diamantino Martins assume uma posição realista em oposição ao idealismo e busca realizar uma síntese entre a Filosofia da Existência e a Filosofia da Essência.

This paper seeks to clarify Diamantino Martins' gnoseological position. Based on an existentialist position the author asserts the failure of Essence Philosophy because it departs from the premise that the relation between ideas, formed by abstraction and disconnected from reality, are the 
centre of gnoseological attention. D. M. assumes a realist position in opposition to idealism and tries to make a synthesis between Existentialist and Essentialist Philosophy.

\section{ÍNDICE}

Keywords: Diamantino Martins, philosophy of knowledge, portuguese philosophy

Palavras-chave: Diamantino Martins, filosofia do conhecimento, filosofia portuguesa

\section{AUTOR}

\section{CRISTIANA DE SOVERAL E PASZKIEWICZ}

Universidade de Trás-os-Montes e Alto Douro/Centro de História da Cultura - Faculdade de Ciências Sociais e Humanas da Universidade Nova de Lisboa

Professora Associada na Universidade de Trás-os- -Montes e Alto Douro. Doutorada em Filosofia da Educação (UTAD, 1997) e mestre em Filosofia (UCP, Brasil, 1988), vem-se dedicando ao estudo da Filosofia em Portugal e particularmente ao Pensamento Educativo Português do século XX. Colaborou na obra História do Pensamento Filosófico Português (Dir. de Pedro Calafate), um projecto do Centro de Filosofia da Universidade de Lisboa, e ainda no Dicionário de Filosofia Portuguesa, projecto da UCP de Lisboa. Publicou estudos sobre vários pensadores portugueses, como António Sérgio, Delfim Santos, Álvaro Ribeiro, Agostinho da Silva, Faria de Vasconcelos, Leonardo Coimbra, Diamantino Martins entre outros. Editou pela INCM A Filosofia Pedagógica de Delfim Santos (2000) e organizou a nova edição, revista e ampliada com edição de inéditos, da Obra Completa de Delfim Santos, F. C. Gulbenkian, Vol. I, 2008; Vol. II, 2009; e Vol. III, 2012.

Associate Professor from the Universidade de Trás-os-Montes e Alto Douro, PhD in Philosophy of Education, MA in Philosophy, she has been dedicated to study Philosophy in Portugal, namely concerning Education. She has published papers and dictionary entries on several Portuguese thinkers and a book on Delfim Santos: A Filosofia Pedagógica de Delfim Santos, Lisboa, INCM, 2000. She was also the organizer of the new edition of the Delfim Santos Complete Works (F. C. Gulbenkian, Vol. I 2008, Vol. II 2009 and Vol.III 2012). 